\title{
La construcción de la "peligrosidad" del migrante: un análisis sobre las representaciones sociales de miembros del sistema judicial en la Ciudad Autónoma de Buenos Aires
}

\author{
The Construction of the "Dangerousness" of Migrants: An Analysis \\ about Social Representations of Judicial System Members in the City \\ of Buenos Aires \\ A construção da "perigosidade" do migrante: uma análise sobre as \\ representações sociais de membros do sistema judicial na Cidade \\ Autónoma de Buenos Aires
}

ANAHÍ PATRICIA GONZÁLEZ*

FECHA DE RECEPCIÓN: 26 DE MARZO DE 2016. FECHA DE ACEPTACIÓN: 10 DE FEBRERO DE 2017

DOI: http://dx.doi.org/10.12804/revistas.urosario.edu.co/sociojuridicos/a.5423

Para citar este artículo: González, A. P. (2017). La construcción de la "peligrosidad" del migrante: un análisis sobre las representaciones sociales de miembros del sistema judicial en la Ciudad Autónoma de Buenos Aires. Estudios SocioJurídicos, 19(2), 63-95. Doi: http://dx.doi.org/10.12804/revistas.urosario.edu.co/sociojuridicos/a.5423

\section{RESUMEN}

El artículo aborda la construcción del imaginario social acerca de los migrantes internacionales que residen en Argentina. Particularmente, se analizan las representaciones sociales prejuiciosas de los miembros del sistema judicial del ámbito de la Ciudad Autónoma de la Ciudad de Buenos Aires con competencia en materia contravencional (Ley 1472), de faltas (Ley 451) y en una limitada cantidad de delitos penales que han sido transferidos a la órbita de la Ciudad en la Argentina con el objetivo de aprehender el proceso de construcción del migrante como sujeto "peligroso". En dicho proceso, se intersectan mecanismos

* Socióloga egresada de la Facultad de Ciencias Sociales de la Universidad de Buenos Aires. Magíster en Investigación en Ciencias Sociales y Doctora en Ciencias Sociales por la Facultad de Ciencias Sociales de la Universidad de Buenos Aires. Docente de la misma universidad y actualmente becaria postdoctoral de Consejo Nacional de Investigaciones Científicas y Técnicas (CONICET) con sede de trabajo en el Instituto de Investigaciones Gino Germani (IIGG), Universidad de Buenos Aires. Correo electrónico: anahipgonzalez@gmail.com 
en los que se produce la estigmatización y culpabilización de los extranjeros en relación a determinados delitos y contravenciones. La consecuencia de este proceso resulta ser la re-creación de la otredad negativa del migrante. Así planteada la cuestión, se analizan los resultados de más de 50 entrevistas realizadas a miembros del sistema judicial en el marco de un Proyecto UBACYT (2010-2014) con sede en el IIGG de la Universidad de Buenos Aires.

Palabras clave: migrantes, sistema judicial, representaciones sociales, prejuicio, estigmatización.

\section{ABSTRACT}

The article discusses the construction of social imaginary about international migrants residing in Argentina. Particularly prejudicial social representations of members of the judicial system of the Autonomous City of Buenos Aires with jurisdiction in contraventions (Law 1472), faults (Law 451) and in a limited number of crimes that have been transferred to the City orbit in Argentina with the aim of apprehending the migrant construction process as dangerous subject are analyzed. In the same mechanisms that stigmatization and scapegoating of foreigners in relation to certain offenses and violations occurs intersect. The result of this process proves to be the re-creation of the negative otherness of migrants. So the question stands, the results of more than 50 interviews with member of the judiciary carried out under a UBACYT Project (2010-2014) based in the IIGG of the University of Buenos Aires are analyzed.

Keywords: Migrants, judicial system, social representation, prejudice, stigmatization.

\section{RESUMO}

O artigo aborda a construção do imaginário social acerca dos migrantes internacionais que residem na Argentina. Particularmente, analisam-se as representações sociais preconceituosas dos membros do sistema judicial do âmbito da Cidade Autónoma da Cidade de Buenos Aires com competência em matéria contravencional (Lei 1472), de faltas (Lei 451) e em uma limitada quantidade de delitos penais que tem sido transferidos à orbita da Cidade na Argentina com o objetivo de apreender o processo de construção do migrante como sujeito "perigoso". Em dito processo, intersetam-se mecanismos nos que se produz a estigmatização e culpabilização dos estrangeiros em relação a determinados delitos e contravenções. A consequência deste processo resulta ser a recreação da alteridade negativa do migrante. Assim apresentada a questão, analisam-se os resultados de mais de 50 entrevistas realizadas a membros do sistema judicial no marco de um projeto UBACYT (2010-2014) com sede no IIGG da Universidade de Buenos Aires.

Palavras-chave: migrantes, sistema judicial, representações sociais, preconceito, estigmatização. 


\section{Introducción}

El fenómeno de las migraciones internacionales ha estado presente a lo largo de la historia de la humanidad y, fundamentalmente, evidencia desequilibrios y contradicciones que acontecen a nivel mundial. En los tiempos actuales, los diversos procesos económicos, culturales, de medios de transporte e información, propios de la globalización, tiñen de características propias las movilidades internacionales. Como respuesta a estos cambios se producen también nuevos interrogantes, perspectivas y aproximaciones sobre las migraciones desde las ciencias sociales. De este modo, se reactualizan estudios sobre las redes y cadenas migratorias, procesos transnacionales de construcción identitaria de los migrantes, etc. Asimismo, las relaciones interculturales, en estas sociedades que se presentan como multiculturales, adquieren aristas de abordaje que antaño no se consideraban. En este marco, cuestiones ligadas a la diversidad, la tolerancia, el diálogo intercultural y el respeto por la "otredad" desplazan a las propuestas de políticas asimilacionistas que se desarrollaban cuando los Estados se hallaban en formación. No obstante, la idea de la época actual como multicultural supone ciertas contradicciones porque:

[...] el hecho de que el ideal de la convivencia armónica entre individuos y grupos con culturas diversas goce de común aceptación en el ámbito teórico parece coexistir sin tensiones con el hecho de que su aplicación fáctica encuentre infinidad de resistencias (Todorov citado por Velasco Arroyo, 2001, p. 118).

De esta manera, el análisis de las relaciones interculturales con tinte negativo se vuelve más complejo, en tanto y en cuanto dichas relaciones son más sutiles y menos evidentes. En el caso del universo de estudio sobre el que se basa la información analizada en el presente artículo se adiciona un grado de complejidad al tratarse de un tipo de institución estatal en el que la igualdad ante la ley resulta fundamental. Esta situación no resulta menor cuando el objetivo de la investigación ha sido conocer cuáles son las representaciones sociales que los miembros de dicha institución (jueces, fiscales, secretarios, prosecretarios, etc.) construyen acerca de los migrantes internacionales y en qué grado intervienen prejuicios, 
estigmatizaciones y preconceptos en la construcción de los imaginarios acerca de los extranjeros dentro del poder judicial de la ciudad de Buenos Aires con competencia en materia contravencional (Ley 1472), de faltas (Ley 451) y en una limitada cantidad de delitos que han sido transferidos a la órbita de la ciudad. Específicamente, el artículo procura presentar los resultados de una investigación realizada en el ámbito de la ciudad de Buenos Aires, focalizado en la eventual construcción del migrante como sujeto "peligroso".

Teniendo en cuenta lo dicho hasta aquí, el artículo posee la siguiente estructura: en primer lugar, a modo de contextualización, se presentan algunas líneas referidas a la cuestión migratoria en Argentina; en segundo lugar, se especifica cuál ha sido la estrategia metodológica llevada a cabo en la investigación marco. A continuación, se analizan los resultados de la pesquisa a partir de los siguientes ejes ordenadores: estigmatización y prejuicios: la asociación entre grupo migratorio y tipo de delitos, la matriz discursiva del racismo cultural y el control social sobre el espacio público. Por último, a modo de cierre, se presentan algunas reflexiones finales.

\section{Algunas líneas sobre la cuestión de las migraciones en Argentina}

En la historia de la edificación de Argentina como nación, las migraciones han cumplido un rol central. Tres son las épocas en las que pueden dividirse las corrientes migratorias recibidas: las migraciones tempranas, abarcan la época colonial, la de independencia y hasta 1880; las de masas, desde 1881 hasta 1914, y las contemporáneas (Devoto, 2003).

El mayor aluvión migratorio se concentra en el segundo periodo cuando "algo más de 4200000 de personas arribaron a la Argentina. Entre ellos, los italianos eran alrededor de 2000000; los españoles, 1400000; los franceses, 170000; los rusos, 160000" (Devoto, 2003, p. 247). Migraciones impulsadas por el Estado, las cuales respondían a los intereses de las élites dirigentes para desarrollar las fuerzas productivas del país. No obstante, se esperaban migrantes provenientes de países como Alemania, Suecia, Francia, etc. Sin embargo, fueron fundamentalmente los migrantes españoles e italianos del sur los que llegaron, muchos de 
ellos, además, portando consigo experiencias e ideologías contestatarias contra el statu quo. Inaugurando el siglo XX se sancionarán dos leyes: la de Residencia (1902) y la de Defensa Social (1910). Ambas leyes establecían la pena de expulsión para los extranjeros que fueran etiquetados como "peligrosos" para el orden social (Costanzo, 2009). Finalmente, la tercera época incluye a las migraciones contemporáneas, las cuales ya no son principalmente de origen europeo, sino regionales.

A nivel normativo, los antecedentes más cercanos son la Ley $\mathrm{Vi}^{-}$ dela (1981), correspondiente al periodo de la última dictadura militar argentina y luego su reemplazo en el 2004, por la Ley N. ${ }^{\circ} 25871 . \mathrm{La}$ primera, permeada por la doctrina de "Seguridad Nacional", perseguía a los migrantes regionales considerándolos "peligrosos" y violaba derechos fundamentales, otorgándole además a la Dirección Nacional de Migraciones (dependiente del poder ejecutivo) la función de determinar la expulsión de extranjeros y a las fuerzas represivas la potestad de controlar y perseguir a los migrantes. Del mismo modo, la normativa no reconocía ciertos derechos (acceso a la salud, a la educación, etc.) para los migrantes, atándolos a la condición migratoria. Por su parte, la sanción de la Ley N. ${ }^{\circ} 25871$ en el 2004, y su reglamentación en el 2010, representan un progreso significativo en el reconocimiento de derechos de los migrantes ${ }^{1}$. Resumidamente, esta normativa supuso la participación del poder judicial en materia de expulsiones, garantizándose así los derechos propios del debido proceso a los migrantes, al tiempo que se iguala a los migrantes y nativos en el reconocimiento de derechos sociales y económicos ${ }^{2}$. No obstante, la Ley N . $^{\circ} 25871$ debe entenderse como un punto de inicio necesario -si consideramos la negación de derechos

1 Para una ampliación sobre esta temática puede consultarse: Courtis, C. (2006). Hacia la derogación de la Ley Videla: la migración como tema de labor parlamentaria en la Argentina de la década de 1990. En E. Jelin E A. Grimson (Comp.), Migraciones regionales hacia la Argentina: diferencia, desigualdad y derechos. Buenos Aires: Prometeo o Novick, S. (2012). Migración y políticas en Argentina: Tres leyes para un país extenso. Revista Voces en el Fenix. (21), 1-35.

2 Dicha cuestión se reactualiza y adquiere nuevas dimensiones a analizar en el caso argentino ya que, actualmente, la administración gubernamental nacional que asumiera en diciembre de 2015, se encuentra impulsando modificaciones en la ley migratoria mencionada que implicarían un endurecimiento del régimen migratorio. Así, el Poder Ejecutivo actual ha emitido un Decreto de Necesidad y Urgencia en el mes de febrero de 2017 (70/2017) que endurece las condiciones migratorias, todo ello acompañado por discursos de funcionarios que vinculan a las migraciones con el delito. 
fundamentales a los extranjeros que suponía la Ley anterior sancionada durante la última dictadura militar - pero para nada suficiente en el proceso de reconocimiento de derechos de los migrantes que residen en el territorio, ya que, dentro de otras variables, las representaciones e imaginarios $^{3}$ sociales, en la sociedad argentina, acerca de los extranjeros y las migraciones (pensados como problema) son reticentes a modificarse.

\section{Estrategia metodológica}

\subsection{Supuestos y fuentes de la investigación}

Tal como se ha explicitado, el artículo se nutre de algunos de los resultados de una investigación de gran envergadura dentro de la Programación UBACYT 2010-20144 titulado "Exclusión, control social y diversidad: articulando la relación entre el migrante externo y las instituciones educativa y judicial", con sede de trabajo en el Instituto de Investigaciones Gino Germani, Facultad de Ciencias Sociales de la Universidad de Buenos Aires, en la que he participado. Este proyecto parte de una serie de hipótesis y ha acumulado considerables resultados en relación a la temática que permiten decir que las relaciones interculturales entre miembros de la sociedad receptora y los migrantes internacionales, en muchos casos, suponen conflictos e intereses que resultan en procesos de exclusión y control social. Asimismo, suponen considerar el entramado de relaciones

3 Otras investigaciones han evidenciado representaciones sociales excluyentes, en relación a los derechos de los extranjeros vinculados a la educación, la salud y el trabajo, con cierto nivel de simetría a las que se encuentran en el presente artículo. Excede las posibilidades de este escrito la tarea de analizar estas cuestiones. No obstante, nos interesa remitir para su consulta la siguiente referencia bibliográfica: Cohen, N. (2010). Representaciones de la diversidad: trabajo, escuela y juventud. Buenos Aires: Ediciones Cooperativas.

4 Este proyecto forma parte de una serie de proyectos UBACYT, todos ellos dirigidos por el Dr. Néstor Cohen, que han tenido y tienen actualmente como objetivo, a través de diversas estrategias metodológicas y universos de estudio, abordar la temática de la interculturalidad a partir del análisis de las representaciones sociales de la población nativa u hospitante sobre el migrante externo. Para conocer algunos de los resultados de estas investigaciones puede consultarse entre otras las siguientes publicaciones: Cohen, N. (2004). Puertas adentro: la inmigración discriminada. Buenos Aires: IIGG, FCS, UBA; Cohen, N. (2009). No es sólo cuestión de migrantes: migraciones externas y exclusión social. En S. Goinheix (Coord.) Conflictos y expresiones de la desigualdad y la exclusión en América Latina. Buenos Aires: El Aleph; Cohen, N. E Mera, C. (2005). Relaciones interculturales: experiencias y representación social de los migrantes. Buenos Aires: Antropofagia. 
de dominación en que se constituye el vínculo con la otredad migrante (González \& Plotnik, 2011).

Por otra parte, las ideas planteadas en este artículo se desprenden de una de las líneas de investigación de mi tesis doctoral, en la que se abordó la cuestión de los Derechos Humanos de los migrantes internacionales. Específicamente, lo que allí planteé es que para que los miembros del poder judicial consideren la posibilidad de que se establezca un reconocimiento desigual de derechos de los migrantes, previamente debe construirse un imaginario en que los extranjeros sean seres extraños, portadores de diferencias intolerables y cosificarlos, en el sentido de considerarlos como "medios para". De esta manera, se toma lo planteado por Balibar (1991), quien sostiene al hablar de "los racismos del futuro", que ningún racismo desaparece sino que muta y propone el término mercancía humana para referirse a los seres humanos que están completamente reducidos al estatuto de cosas, incluyendo entre ellos a los migrantes en búsqueda de lugares donde ser "utilizados". En ese proceso de borrado del reconocimiento de derechos de los migrantes debe darse una primera ruptura, en la que confluyen procesos de estereotipación, estigmatización y esencialización de la identidad migrante, que permita que sea, al menos, pensable delimitar su igualdad frente al nativo, designarle una "igualdad virtual", transfigurándose de esta manera la diferencia en desigualdad.

La unidad de análisis de la investigación ha sido el sistema judicial, empleándose fuentes de información primaria. Se entrevistó a miembros del poder judicial de la Ciudad Autónoma de Buenos Aires, resultando una muestra de 55 entrevistas realizadas bajo la técnica de entrevista en profundidad. Para ello se diseñó una guía de pautas con preguntas de respuesta abierta que fue empleada para todos los entrevistados. El número final de las entrevistas resultó de la implementación metodológica conocida como saturación teórica de la muestra, que Strauss definiera como el momento en el cual el crecimiento muestral no contribuye a nada nuevo al interior de las categorías de análisis (Strauss \& Corbin, 2002). Se optó por la técnica de entrevista en profundidad dado que el objetivo era conocer las representaciones sociales que los miembros del poder judicial construyen y reconstruyen sobre los migrantes, disminuyendo lo más posible el nivel de reactividad de la respuesta (Cea D'Ancona, 
2005) dado lo "sensible" del tema ya que, como es sabido, "discriminar no está bien"5. La estrategia de investigación, a partir de las representaciones sociales, ha sido llevada a cabo en varias indagaciones por el mismo equipo de investigación, lo que ha permitido contar con un bagaje de experiencia de campo importante. La guía de pautas confeccionada constó de una serie de dimensiones ${ }^{6}$, las cuales incluyeron una serie de preguntas relativas a la problemática en cuestión.

Las entrevistas fueron desgrabadas de manera textual, e incorporadas a un matriz de datos a través del uso del programa ATLAS.ti. La elección de este programa permitió, dada sus características, llevar adelante el análisis bajo el método de comparación constante (Strauss \& Corbin, 2002). Para el análisis fue utilizada una de las funciones del programa ATLAS.ti que permite filtrar por nacionalidades así como identificar las menciones de atributos según el grupo migratorio. Hubo un interés en identificar una tendencia en los rasgos que son asociados a los grupos migratorios y no contabilizar la frecuencia de las menciones, ya que ello requeriría otro tipo de muestreo del que se ha realizado (basado en la saturación teórica de la muestra) como se ha especificado. De lo que se trata es de analizar cuándo y cómo son visibilizados los migrantes por parte de los operadores judiciales entrevistados, en relación a qué atributos y vinculados a qué "desviaciones", así como aprehender las explicaciones que los mismos construyen acerca de sus "asociaciones" entre el extranjero y su "peligrosidad" potencial como colectivo.

5 Escapa a los objetivos del presente artículo abordar la cuestión de los desafíos metodológicos que la investigación ha tenido. Sobre este aspecto de la indagación puede consultarse: Plotnik, G. E González, A. (2012). El sesgo de deseabilidad social en el abordaje del fenómeno de la discriminación en las relaciones interculturales: algunas reflexiones sobre las guías de pautas como "teorías en acto". VII Jornadas de Sociología de la UNLP. La Plata: UNLP.

6 Las dimensiones han sido: 1) percepción de las migraciones tradicionales, 2) percepción de las migraciones recientes/actuales, 3) componentes socioeconómicos y étnicos en relación al origen nacional, 4) funcionamiento de la justicia y 5) migraciones, identidad y Nación. Un análisis más elaborado del instrumento de registro empleado puede consultarse en Plotnik, G., G González, A. (2012). El sesgo de la "deseabilidad social" en el abordaje del fenómeno de la discriminación en las relaciones interculturales: Algunas reflexiones sobre las guías de pauta como "teorías en acto". VII Jornadas de Sociología de la UNLP. La Plata: UNLP. 


\subsection{Acerca de la unidad de análisis}

Respecto al sistema judicial, como unidad de análisis, es preciso explicitar que el mismo presenta algunas irregularidades. En primer lugar, consideramos que las relaciones interculturales, entre migrantes y miembros de la sociedad receptora, son un fenómeno que a la vez excede, atraviesa e interpela al poder judicial. En segundo término, se entiende aquí al sistema judicial, tomando la definición de Bourdieu (2000), como un campo (con sus propias leyes, agentes, que tienen determinado habitus, que ocupan diversas posiciones y portan ciertos capitales por los que se lucha) que se encuentra en relación con otros campos dentro del espacio social. Ahora bien, lo central de la efectividad simbólica y material que el sistema judicial tiene en la sociedad radica, por un lado, en las competencias que detentan sus miembros frente a los legos $y$, por otro, la hegemonía que ha adquirido como regulador de los conflictos legales. Es decir, en la época feudal existían una multiplicidad de instancias jurídicas y legales: se hallaba el derecho canónico, el señorial, el real, el urbano y el mercantil. Progresivamente, y partir de la necesidad del sistema económico, se precisaba disminuir la confusión y complejidad de dichos sistemas para conseguir mayor previsibilidad, centralizándose y monopolizándose el ejercicio de la administración judicial en el Estado y sus instituciones.

En Argentina, el proceso de "modernización jurídica", supuso un proceso intrincado y complejo a partir del cual el Estado iría expropiando a otras instancias - en un gradiente que incluye representantes de esas funciones desde autoridades indígenas hasta eclesiásticas - funciones represivas y judiciales. De esta manera, "detrás de la Constitución de 1853 (y de la unificación jurídica fundamental en 1860), se sancionan un Código de Comercio (1863), un Código Civil (1869), y un Código Penal (1 887)" (Caimari, 2007). Estos modos de normativizar y constituir instancias de control y administración de "justicia" se irán imbricando y constituyendo al sistema judicial como poder estatal productor de normalidad y de sujetos de derecho. Asimismo, como en todo proceso de normalización, se efectuarán inclusiones y exclusiones.

En suma, la relevancia de abordar la cuestión de las relaciones interculturales entre nativos y migrantes en un espacio como el judicial resulta 
evidente frente a la estatalización de la administración de la justicia que rige actualmente en sociedades como la nuestra. Asimismo, resulta pertinente realizar algunas especificaciones acerca de la justicia de la Ciudad Autónoma de Buenos Aires, de esta manera:

El artículo 107 de la Constitución de la Ciudad de Buenos Aires otorga al Poder Judicial local un diseño moderno integrado por cuatro órganos: El Tribunal Superior de Justicia - compuesto por cinco magistrados designados por el Jefe de Gobierno con acuerdo de dos tercios del total de los miembros de la Legislatura-; el Consejo de la Magistratura, integrado por nueve miembros -tres representantes del Poder Legislativo elegidos por el Parlamento con el voto de al menos 40 diputados, tres jueces en representación del Poder Judicial elegidos por el voto directo de los magistrados locales excepto los miembros del Tribunal Superior, y tres representantes de los abogados matriculados en la Ciudad de Buenos Aires elegidos por sus pares-; el Ministerio Público conformado por tres áreas -el Ministerio Público Fiscal, el Ministerio Público de la Defensa y el Ministerio Público Tutelar-; y los Tribunales que la ley establezca, integrados por jueces y juezas seleccionados por concurso público de oposición y antecedentes, y designados con el voto de la mayoría absoluta de la Legislatura a propuesta del Consejo de la Magistratura (Poder Judicial de la Ciudad de Buenos Aires, s.f.).

Una representación más esquemática del organigrama se puede ver en la figura 1.

Por otra parte, resulta importante aclarar que existen actualmente dos fueros en el poder judicial de la Ciudad: el Contencioso Administrativo y Tributario y el Penal, Contravencional ${ }^{7}$ y de Faltas $^{8}$. Específicamente,

7 Se rige por lo establecido por el Código Contravencional de la CABA. En vinculación con la temática abordada en el presente artículo, por ejemplo, dicho Código regula el uso del espacio público (Código Contravencional, 2004).

8 "En el Fuero Penal, Contravencional y de Faltas tramitan las causas por aplicación del Código Contravencional de la Ciudad de Buenos Aires, el Régimen de Faltas y la legislación en materia penal correspondiente a una serie de delitos transferidos por medio de convenios de la Justicia Nacional a la Justicia de la Ciudad. Este fuero está conformado por 31 juzgados de Primera Instancia y una Cámara de Apelaciones integradas por 10 jueces, uno de los cuales ejerce la presidencia y 9 integran tres Salas con 3 vocalías cada una. También forman parte de este fuero 40 Fiscalías de Primera Instancia y 5 de Cámara; 24 Defensorías de Primera Instancia y 2 de Segunda Instancia; y 2 Asesorías Tutelares de Primera Instancia y 1 ante la Cámara de Apelaciones" (Poder Judicial de la Ciudad de Buenos Aires, s.f.) 


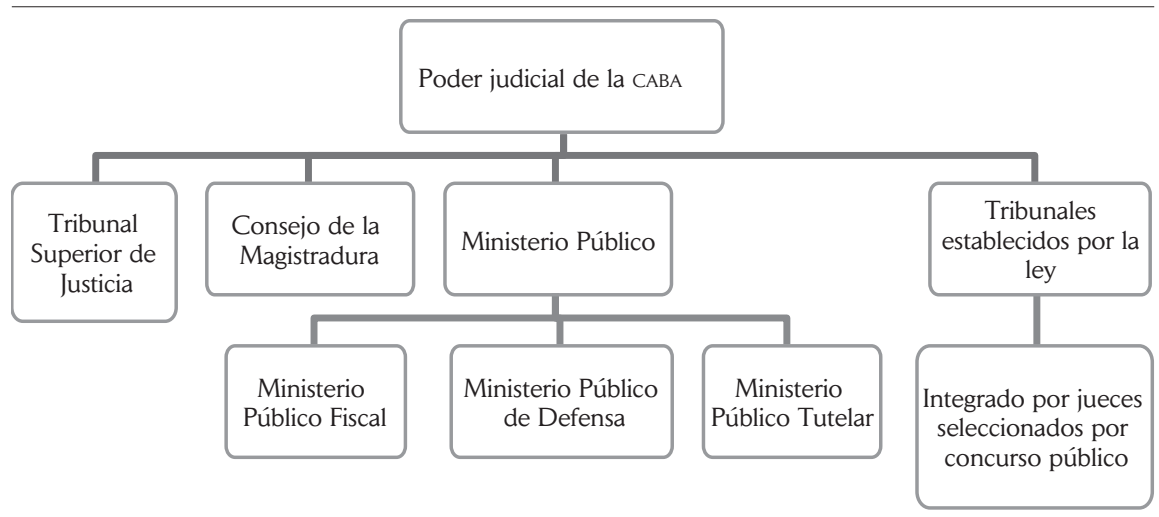

Fuente: elaboración propia con base en información recuperada de la página web del Poder Judicial de la Ciudad Autónoma de Buenos Aires (2016)

las entrevistas fueron realizadas a miembros del segundo de estos fueros. También se efectuaron, se efectuaron entrevistas a miembros del Ministerio Público Fiscal ${ }^{9}$ que intervienen impulsando e investigando delitos y contravenciones y cuya competencia corresponde a la justicia de la CABA. Dicha justicia se crea a partir de la declaración de la autonomía porteña y de la sanción de Constitución de la Ciudad de Buenos Aires en 1996 que estableció que la Ciudad adoptaba un sistema de división de tres poderes: el ejecutivo y el legislativo que ya existían, bajo los nombres de Intendencia y Concejo deliberante, son ahora denominados Jefatura de Gobierno y Legislatura, respectivamente. De este modo se crea, como un poder enteramente nuevo, el Poder Judicial de la Ciudad de Buenos Aires. Las competencias de este poder han ido creciendo paulatinamente desde su creación y, si bien se encuentra casi terminado, aún continúan aumentando. En relación a la temática del artículo, si bien este fuero no interviene

Por otra parte, los delitos transferidos al momento son, entre otros: lesiones, amenazas, usurpación, daños, etc. Para mayor información sobre el proceso de traspaso de competencias que aun continúa, ver el Informe 752 sobre delitos ingresados al fuero contravencional penal y de faltas de la Ciudad de Buenos Aires, período 2008/2013 de la Dirección General de Estadísticas y Censos.

9 Entre las funciones del Ministerio Público Fiscal se encuentran: "Promover la actuación de la justicia en defensa de la legalidad y de los intereses generales de la sociedad, impulsar las acciones penales y contravencionales, velar por la normal prestación del servicio de justicia y procurar ante los tribunales de la Ciudad la satisfacción del interés social; mediante la investigación de los delitos y contravenciones cuya competencia fue transferida a la Ciudad Autónoma de Buenos Aires, formular su acusación ante los jueces, proponer soluciones alternativas a los conflictos" (Fiscalía de la Ciudad de Buenos Aires, s.f.). 
de modo directo en todos los aspectos que la cuestión migratoria supone (ninguno podría hacerlo, por cierto, dada la complejidad del fenómeno), sostenemos que forma parte del entramado de instituciones estatales, en general, y judicial ${ }^{10}$, en particular, que coadyuvan en los modos en que el Estado gestiona y administra la cuestión migratoria, resultando en un tipo particular de tratamiento de la diversidad y las relaciones interculturales que se establecen entre nativos y miembros de la sociedad de acogida. Específicamente, si consideramos que se trata de instancias elegidas dado su rol punitivo y de "control social", podrá evidenciarse, en los testimonios de los entrevistados, cuáles son sus percepciones sobre los extranjeros en asuntos vinculados con contravenciones, delitos y cuestiones relacionadas con el uso "apropiado" del espacio público, entre otros.

\subsection{Acerca de la categoría de representaciones sociales}

Para cerrar este apartado teórico-metodológico de la investigación, en relación a lo dicho anteriormente, cabe recordar que se analizarán representaciones sociales, entendiendo a las mismas como herramientas analíticas, a partir de las cuales interpretar los imaginarios que los entrevistados re-construyen sobre la otredad migrante. Se parte de la definición de representación en la que se vinculan los procesos simbólicos con las conductas, ya que se produce un proceso de elaboración cognitiva y simbólica que orienta los comportamientos con el objeto de aumentar la previsibilidad del mundo (Berger \& Luckmann, 2006; Jodelet, 1991). En ese proceso de hacer más previsible la realidad es en el que se despliegan procesos de clasificación de los "otros". Se establecen diferencias que en sí mismas no implicarían desigualdades. Sin embargo, éstas surgen cuando las clasificaciones son jerarquizantes. A partir de allí, las representaciones sociales no resultan ya inocuas recetas para la acción, reactualizándose

10 Es decir, la "cuestión migratoria" interpela -al tiempo que excede- a todo el sistema judicial, tal como lo manifiesta una de las entrevistadas que actuó como informante clave, antes de comenzar con el trabajo de campo propiamente dicho con los miembros del poder judicial: "esta ley [la de migraciones] mezcla todo, atraviesa todo, entonces si cada uno está mirando su quintita y te aparece un procedimiento como el de trámite de expulsión, donde va pasando por diferentes instancias[...] está primero en el ámbito tribunal oral, después va al ámbito administrativo después va al ámbito de ejecución penal, en el medio tenés al Servicio Penitenciario, o sea, tenés tantas instituciones involucradas por la burocracia propia de cada institución donde se complica" (Ministerio Público de la Defensa, 2013). 
y anclándose en las imágenes, pensamientos e ideas propias del sentido común, sino que estructuran relaciones de dominación.

A partir de la perspectiva teórico-metodológica, explicitada en este apartado, se ha llevado a cabo la investigación y luego abordado el análisis de los resultados de la misma. En las páginas que siguen nos adentraremos en la presentación de los datos que se han logrado recabar.

\section{Resultados}

Como se ha hecho mención, en la investigación se indagó acerca de las representaciones sociales de miembros de una institución, en la que la idea de igualdad de las personas ante la ley, constituye uno de sus pilares. No obstante, entre los roles principales que el sistema judicial también tiene, esta el de administrar los ilegalismos y, en ese accionar, la idea de control social resulta imposible de soslayar. Se entiende dicho control como:

[...] el proceso (histórico) de construcción de la relación entre poder y desviación: poder de definir las normas y de etiquetar a quien de ellas se desvía, poder de inducir conformidad y de reprimir disconformidad, poder de trazar la diferencia entre lo normal y lo patológico, poder de corregir castigando y de castigar corrigiendo (De Giorgi, 2005, p. 38).

Teniendo presentes estas funciones del sistema judicial interesa ahora analizar cuáles son las representaciones sociales que miembros del sistema judicial (en los fueros especificados anteriormente) tienen sobre los migrantes internacionales en relación a la tarea de control social que desempeñan.

\subsection{Estigmatización y prejuicios: la asociación entre grupo migratorio y tipo de delitos}

El prejuicio es definido por Wieviorka (1992) como una forma elemental de racismo que se vincula con el reforzamiento de desigualdades existentes entre los sujetos involucrados. En el caso de extranjeros y nativos, es el primero - en tanto miembro y representante de una institución estatal- quien tiene la potestad de catalogar al migrante. En 
este sentido, en las entrevistas se instituyen estereotipos de migrantes. Estereotipar es reducir a los sujetos a unos pocos rasgos esenciales fijados por la naturaleza. Asimismo, como práctica significante, se le añaden una serie de elementos más: posee un efecto de exclusión, es decir, expulsa a quien ha estereotipado y lo coloca en un lugar desigual, de inferioridad. Por otro lado, esta situación suele suceder donde existen desigualdades de poder, al tiempo que supone la circularidad y ambivalencia del mismo. Por último, incluye elementos de fantasía y fetichismo (Hall, 1997). En suma, el estereotipo fija, determina y coloca en un lugar al sujeto, representado como diferente, en una situación de la que es poco probable que pueda salirse.

¿Cuáles son los "rasgos esenciales" atribuidos por los entrevistados a las comunidades migratorias sobre las que se indagó? ¿De qué modo responden a representaciones prejuiciosas sobre las mismas? A continuación, algunas de las manifestaciones discursivas de los entrevistados:

Creo que puntualmente es la idiosincrasia de ellos [paraguayos], si creo que es un factor, por lo general, que se genera por el tema de los festejos, son personas que son muy bebedoras y tienen una idiosincrasia que siempre tienen que estar armados con algún cuchillo o armados con armas de fuego y entonces creo justamente que es por la cultura de ellos (Entrevista a Secretaria, 13 años en el sistema judicial, 2011).

[...] lo que veo es que muchas veces los bolivianos tienen un tema de que son muy sumisos, no son de alzar la voz si se ven en una situación en la que se ven desprotegidos porque obviamente no tienen nada que perder, digamos, vienen a trabajar acá donde sea como sea, a eso iba más que nada con que tienen esa costumbre, digamos, de ser más bien sumisos y eso les juega en contra porque los ponen a trabajar de lo que sea y en condiciones bastante malas y no se quejan, por así decirlo (Entrevista a Oficial, 4 años en el sistema judicial, 2011).

Por ahí el coreano está más relacionado con la explotación de sus propios trabajadores, son más de asociarse ilícitamente, o sea mafia, por decirlo de alguna manera y el paraguayo o el boliviano o el peruano por ahí actúa solo [...] en cuanto a los asiáticos de la explotación del trabajo, y eso es muy cultural de ellos (Entrevista a Prosecretaria, 20 años en el sistema judicial, 2012). 
Asimismo, el estereotipo se emparenta con el proceso de estigmatización. La teoría del estigma asume una predisposición de la conducta, un atributo que induce a la realización de determinadas prácticas (los bolivianos, soportan la explotación; los coreanos, fomentan la explotación de sus trabajadores). Además, al estigmatizar se postulan teorías acerca de la "naturaleza original" del sujeto estigmatizado, remitiéndose a atributos esenciales ligados a la moralidad y la no-virtud. El concepto de estigma se refiere a cierta característica que "se interpreta como signo visible de iniquidad o depravación moral. Por otra parte, el rasgo inocuo deviene en mácula, un signo de tormento, un motivo de deshonra" (Bauman, 1996, p. 111).

La fijación y adjudicación de determinados atributos, como se percibe en los fragmentos de las entrevistas citadas arriba (paraguayos, violentos; bolivianos, sumisos; asiáticos, explotadores) se traslada al tipo de delito que serían proclives a cometer, según los testimonios, cada una de las comunidades migrantes.

[...] por lo que veo, no es por discriminar ${ }^{11}$, pero es como que mayormente la gente que viene de Perú, o de Paraguay como que suelen incurrir en el mismo tipo de delitos, como en lesiones o hurtos. Es como que hay un $\mathbf{8 0} \%$ de esos delitos que son cometidos por extranjeros, como chilenos también, hay un $20 \%$ que son argentinos. Desde que yo estoy, hace 5 años hasta acá, siempre fue igual, no sé antes, si antes hubo esta cantidad de gente que viene de estos países limítrofes había o no la misma cantidad de delitos. Por lo que tengo entendido, no. Como que creció, cada vez que pasa el tiempo crece más. No es que hay menos, hay más delitos y bueno, caracterizado por el tipo, o sea, de las personas de estas nacionalidades (Entrevista a Secretario, 5 años en el sistema judicial, 2011).

Bueno, tiene que ver también, como decía antes, por su cultura y por las cosas que, a ver, uno cuando viene de otro país, trae todo, trae lo bueno y lo malo y su cultura misma, o sea trae lo bueno y lo malo de

11 El tipo de aclaraciones tales como: "no es por discriminar", "puede sonar un poco discriminatorio", "no es por estereotipar" aparece en varias de las entrevistas. En sus investigaciones sobre historias e imaginarios prejuiciosos Van Dijk (1997, p. 187) concluía que "mientras que las personas con prejuicios tenderán a afirmar repetidamente que por supuesto no son racistas, las personas antirracistas no tendrán necesidad de presentarse bajo esta faz positiva. Sus propias historias y argumentos muestran su posición". 
su cultura misma. Entonces es como que hay ciertos delitos que están relacionados con cierta inmigración porque sabemos que ese tipo de delito o ese tipo de ilicitud son más de tales comunidades o de tal población. Por ejemplo, si hablamos también del narcotráfico. Y... uno de los principales lugares adonde nos vamos a remitir va a ser Colombia (Entrevista a Oficial Primera, 8 años en el sistema judicial, 2012).

Porque estas denuncias a veces se hacen desde las villas y ahí en las villas como no hay mucho control, no existe un control exhaustivo de esto que digo del sistema migratorio, generalmente hay gente de nacionalidad paraguaya, boliviana. Entonces vos podes percibir el tema de los conflictos y la nacionalidad desde ahí (Entrevista a Directora Área de Denuncias, 15 años en el sistema judicial, 2010).

Sí, sí. Delitos o contravenciones sí. Hay ciertos rubros que en los que comúnmente encontrás inmigrantes porque generalmente siempre son trabajo que son en negro que son como trabajos de paso y ellos pueden acceder más fácil a eso y la persona que los contrata también los tiene más a la mano digamos, que son desde la famosa mafia de las flores, que esta manejado por peruanos, tal vez sea casualidad, pero acaparaban ese rubro [...] eso es una contravención, está penado, uno no puede vender lo que quiere en la calle porque tiene que pasar por ciertos controles bromatológicos y estos, esta clase de vendedores no pasan esos controles, eso puede ser uno, la venta ambulante (Entrevista a Oficial, 4 años en el sistema judicial, 2010).

Como se ve en las entrevistas, las características atribuidas a cada colectividad migratoria posibilita su asociación con determinada práctica por fuera de la norma, ya sean delitos infracciones, contravenciones, faltas a la "moral y las buenas costumbres", etc. En dicha asociación pueden verse cómo son caracterizados los migrantes por parte de los miembros del sistema judicial. Es plausible reconstruir una mirada "cargada de sentido" que se proyecta en cada colectividad migrante y sus miembros, imbricándose las cuestiones de los "ilegalismos" con el control migratorio:

[...] creo que en el 2005 hubo una ley, que se llama Ley Patria Grande, que es como que sensibilizó y atenuó todas las cuestiones vinculadas a los extranjeros. Por ejemplo, en materia contravencional, si una persona tiene un montón de causas por contravenciones, por venta ambulante, por oferta de sexo en la vía pública no hay un mecanismo igual 
a través del área de migraciones que lleve un control y que haga que lo deporten por esa circunstancia. Entonces en eso es como que uno es crítico porque ve mucha gente que viene y están ilegales ${ }^{12}$ y por ahí viven en las villas. Hay comunidades, hay comunidades bolivianas en el Bajo Flores, crecieron un montón y no hay un control migratorio que sea categórico (Entrevista a Secretaria, 15 años en el sistema judicial, 2011).

Un control. Si una persona que, que tuvo antecedentes, no permitirle entrar. Y darle, llevarle un control de que esa persona que, realmente, llegue acá, se establezca, tenga dónde vivir, no usurpe casas, consiga un trabajo, que se le haga un control de buena conducta. Me parece que es una manera también de proteger, que haya menos delincuentes. O sea, ya tenemos bastante nosotros cómo para encima, sumar de otros países. Y porque la mayoría de la gente [extranjera] no está pagando impuesto, no está contribuyendo. O sea, nos perjudica (Entrevista a Prosecretaria, 18 años en el sistema judicial, 2010).

De esta manera, algunos de los entrevistados afirman que, si bien no cuentan con datos estadísticos al respecto, ellos pueden realizar la vinculación entre cierto grado de "peligrosidad" o "desviación" (violencia, miedo) y determinadas colectividades migratorias. Estas representaciones se arraigan en conocimientos del sentido común y son reproducidas en la experiencia cotidiana. En tanto organizador de la vida "de todos los días" de las personas, las representaciones sociales, constituyen modalidades de pensamiento que disminuyen la incertidumbre en las relaciones con los "otros". Empero, si bien se inscriben en saberes del sentido común al mismo tiempo, los discursos que analizamos son elaborados por miembros de un espacio, como el judicial, ungido de un poder de nominación, calificación y clasificación con efectos de verdad. Aquí, la línea divisoria entre ser un "saber útil", en tanto organizador de líneas de acción en la vida diaria, a convertirse en un prejuicio con consecuencias materiales, resulta no ser tan profunda.

[...] son cuestión... son asociaciones, creo que más... estereotipadas. Habría que sentarse realmente a hacer unas estadísticas puntuales

12 El término "ilegal" en materia migratoria ha sido criticado desde diversas instancias y perspectivas que defienden el derecho a migrar como derecho humano, connotándose que ningún migrante es "ilegal", en todo caso debiera hablarse de una irregularidad administrativa. 
de asociar y tener la seguridad con cada uno puntual. Lo que siempre te dicen es eso... no sé... si hay un ladrón uruguayo, generalmente, es boquetero ${ }^{13}$. Porque son, te dicen: «el que sabe hacer boquetes es el uruguayo». Cada tanto aparece algún boquete y dicen: «uh, justo era uruguayo», entonces todo el mundo "ah, sí... entonces la asociación tiene razón». Pero, hoy en día, por lo menos de la inmigración actual, a los que más miedo se le tiene es a la gente peruana. Por la violencia, y por la manera en que manejan los problemas y las cosas. Y por el poco apego a la ley que tienen (Entrevista a Prosecretario, 4 años en el sistema judicial, 2010).

Este fragmento permite evidenciar un punto que interesa resaltar respecto a los discursos de los entrevistados. Dada la temática "sensible" sobre las que se indaga, los miembros del sistema judicial en ocasiones ubican en "otros" el discurso prejuicioso (representado en las frases: "Lo que siempre te dicen", "te dicen..."), sin embargo, al analizar la totalidad, de las entrevistas, el sujeto entrevistado retoma el discurso como propio: "Pero, hoy en día, por lo menos de la inmigración actual, a los que más miedo se le tiene es a la gente peruana. Por la violencia, y por la manera en que manejan los problemas y las cosas. Y por el poco apego a la ley que tienen". Luego, nuevamente, se coloca el discurso discriminatorio "fuera". Por ende, se produce un movimiento oscilante en las argumentaciones entre asumir esa mirada como propia y adjudicarla a otros.

Las representaciones sociales permiten evidenciar cuáles son las imágenes acerca de los "otros", en este caso migrantes externos, que permanecen, se refuerzan y reactualizan en el imaginario social. Entendiendo a este último como universos de significaciones que instituyen una sociedad, resulta inseparable de la cuestión del poder. En términos de Baczko (1999, p. 16),

[...] el ejercicio del poder, en especial del poder político, pasa por el imaginario colectivo. Ejercer un poder simbólico no significa agregar lo ilusorio a un poderío "real", sino multiplicar y reforzar una domina-

13 Dicho término, perteneciente al lunfardo argentino, refiere a aquellos ladrones que se especializan en realizar perforaciones para entrar a comercios o bancos con el fin de robar. 
ción efectiva por la apropiación de los símbolos, por la conjunción de las relaciones de sentido y de poderío.

Recapitulando, puede afirmarse que, más allá de las especificaciones realizadas a cada colectividad, todos los migrantes se aúnan en las representaciones reconstruidas en el sistema judicial por su calidad de "extraños". La extrañeza está ligada a un suceso imprevisto y desestructurante. Supone el establecimiento de una relación social, ya que no hay extraños en sí mismos, sino extraños para alguien (Sabido, 2009). O retomando las palabras de Santamaría (2002, p. 94) refiriéndose a "la condición de extraño no es algo fijo ni natural, no es algo consustancial a ciertos individuos o grupos, ni a las conductas que estos tienen, sino una posición que no sólo es relativa sino también relacional y mudable". Aquella presencia "desestructurante" de los migrantes se transfigura, a los ojos de quienes conforman el sistema judicial, en situaciones conflictivas.

En el sistema judicial hay conflictos que se producen por los inmigrantes.

Entrevistador: ¿Como cuáles?

Simplemente lo que encuentro es una llegada de inmigrantes con conflictos. No sé si porque llegaron a un lugar donde también es un lugar conflictivo, como es la Capital Federal o ellos son conflictivos. Pero sí han generado conflictos (Entrevista a Prosecretario, 7 años en el sistema judicial, 2012).

Como ya hemos hecho mención, en las manifestaciones acerca de la extrañeza de los migrantes se reproduce un racismo de tipo "cultural", es decir no se asienta en argumentos de tipo biologistas sino que se ensayan explicaciones a partir de las pautas culturales de cada comunidad migratoria.

\subsection{La matriz discursiva del racismo cultural}

Balibar (1991) refiere a un "racismo sin razas" o "racismo diferencialista" que se basa en la constatación de que el naturalismo genético no es el único modo en que pueden naturalizarse los comportamientos humanos 
y las pertenencias grupales, sino que "la cultura puede funcionar también como una naturaleza, especialmente como una forma de encerrar a priori a los individuos y a los grupos en una genealogía, una determinación de origen inmutable e intangible" (p. 38). Ello, aparentemente abandonándose el modelo jerárquico propio del racismo biologicista. Se promueve que todas las culturas deben ser toleradas pero, con el fin de evitar conflictos y prevenir el racismo, también resulta imperioso evitar los contactos. Estas teorías, denominadas diferencialistas, parten de la "comprensión" hacia el fenómeno de rechazo de la otredad en tanto hecho inevitable. Es decir, la agresividad y la violencia hacia la diferencia forman parte de esta nueva manera de comprender el fenómeno del racismo (Balibar, 1991). Se trata de un proceso de naturalización del comportamiento racista, donde el recurso a la cultura para explicar las desigualdades económicas, de poder, culturales, etc., que se establecen con la otredad (en este caso migrante) ha llevado a algunos autores a hablar de "fundamentalismo cultural", a partir del cual, las explicaciones sobre los fenómenos de segregación de migrantes, por ejemplo, se arraigan en variables vinculadas a conflictos culturales. Ello supone dos cuestiones. En primer término, la preeminencia de la cultura, como variable de clarificación de los fenómenos sociales, se enlaza con la idea de que vivimos en épocas multi e interculturales $y$, por tanto, ese florecimiento de las identidades interpela a las ciencias sociales a plantearse nuevas y complejas preguntas. Sin embargo, y esta es la segunda cuestión a tener en cuenta, esa preeminencia puede ocultar procesos para los cuales la "caja de herramientas" clásica de las ciencias sociales aun es más que necesaria. Con todo, que los entrevistados se expliquen (justifiquen) ciertos procesos de dominación y criminalización de grupos migratorios a partir de la cultura de esos colectivos indican de qué modo las explicaciones culturalistas (científicas) han hecho mella en el conocimiento del sentido común.

Y la pauta cultural es hasta la violencia o la forma de dirimir conflictos internos, parecería que allí ellos no lo dejaran en Ezeiza, lo trajeron, entonces si hay un pase de factura entre ellos, vas a encontrar a un sicario que entra, como pasó el otro día, en principio, a un supermercado chino y asesina, cometiendo el homicidio con un grado de violencia que, vos te quedás diciendo «bueno, tiene color a una cosa interna» [...] Te quie- 
ro decir que me da la sensación que esta migración coreana, china que se está insertando, te diría que vienen con un nivel económico mucho mayor que los países de acá, porque tienen la posibilidad de instalar un negocio propio, da la sensación que, a la vez, importan o traen consigo esas prácticas culturales, sociales que tenían en sus países de origen (Entrevista a Secretario, 23 años en el sistema judicial, 2010).

Hay ciertas características culturales, que si llegan a delinquir, por ahí, vos sabés más, para qué lado pueden llegar a ir más que para otro (Entrevista a Secretario, 12 años en el sistema judicial, 2011).

La referencia a "valores", "idiosincrasia", "pautas culturales" permite justificar la estigmatización de determinados colectivos de migrantes, arraigando al prejuicio y la desvalorización de los extranjeros, por momentos culpabilizándolos y, por otros, inferiorizándolos. En ambas ocasiones subyace la idea de una moralidad distinta entre nativos y extranjeros.

[...] en algún caso que tuve un paraguayo, veía normal agarrarse a puñaladas, hay ciertos valores que son diferentes a los nuestros y eso hace que el concepto de honor para nosotros es uno y para un boliviano es otro y para un chileno es otro y para un español es otro, digamos, son conceptos que por ahí no son tan fáciles de definirlos pero sí de sentirlos, digamos (Entrevista a Fiscal, 10 años en el sistema judicial, 2010).

En cuanto a la incidencia del delito del extranjero, hay determinadas clases de delitos que se suelen ver más cometidos por extranjeros, como pueden ser, por ejemplo, todos los que son vinculados a lesiones o peleas callejeras o cuestiones de violencia doméstica, es bastante más habitual verlos cometidos por extranjeros, sobre todo peruanos, que por argentinos. Quizás por una cuestión cultural porque ellos tienen como una costumbre de manejarse de una manera bastante distinta a la costumbre que tenemos nosotros (Entrevista a Jefa de despacho, 7 años en el sistema judicial, 2011).

De esta manera, haciendo nuestras las palabras de Wieviorka (2002, p. 125) se puede sostener que, en muchos casos, y las entrevistas así lo denotan,

[...] se ha pasado de los prejuicios declarados a formas más sutiles que constituyen un racismo simbólico de características muy particulares: 
rechazo de los estereotipos burdos y de la discriminación más aparente, repulsa del cambio radical por razones ostensiblemente no raciales.

Se configura, de este modo, una matriz de explicaciones racionales acerca de la asociación entre grupos migratorios y ciertos delitos, ancladas en "la cultura", pero, para el caso del migrante es esencialmente negativa, sin nada que aportar, aun más, causante de desviaciones, delitos y contravenciones. El dato de la pertenencia del extranjero a una "comunidad nacional" diferente (con sus características particulares, sus tradiciones, incluso sus símbolos patrios, festividades, etc., que -en los "tiempos multiculturales" que corren- son realzados como uno de los atributos de las sociedades cosmopolitas de hoy) estructura la construcción que hacen los entrevistados sobre las identidades migrantes y en ocasiones, dicha diversidad puede ser valorada positivamente por los nativos. No obstante, el migrante es también constituido como "otro" cuya extranjeridad se define en oposición al "nosotros" de los nativos. En momentos en que se requiere, esa extranjeridad se carga de sentidos negativos y las relaciones interculturales entre unos y otros participantes adquieren un cariz diferente, ya que quienes tienen la potestad de encasillar al "otro" ejercen el poder material y simbólico de convertir las diferencias en desigualdades. Es así que:

El Otro, desde este punto de vista, es definido por el grupo "racista" como diferente por su tradición, su nación, su religión, su lengua, su historia, y esta diferencia, irreductible constituiría una amenaza tal para el grupo en cuestión que éste, en contraposición, reclama discursos y prácticas de segregación, de expulsión o de destrucción (Wieviorka, 2002, p. 290).

Uno de los modos de aprehender de qué manera se procura segregar o excluir al grupo que ha sido etiquetado como una amenaza es analizando los mecanismos por medio de los cuales el Estado - en este caso el sistema judicial- pretende o intenta controlar el espacio público que, en el caso de la ciudad de Buenos Aires, remite al Código Contravencional vigente y aplicado por la justicia local a la cual pertenecen los entrevistados. 


\subsection{El control social sobre el espacio público}

La construcción de la otredad migrante como "peligrosa" se vincula también con el espacio porque "si el extranjero es «el otro", no aparece más que en el encuentro. Los aislados en islotes, privados de toda relación humana, ignoran que haya extranjeros" (Gaudemet, 1988 en Santamaría, 2002, p. 56). A su vez, el lugar por excelencia donde pueden encontrarse nativos con quienes no lo son es el espacio público. Se entiende a este último como "un ámbito contenedor de la conflictividad social, que tiene distintas posiciones dependiendo de la coyuntura y de la ciudad que se trate" (Carrión Mena, 2004, p. 61). Las definiciones de las posiciones que ocupan los sujetos en ese espacio determinan el mayor o menor ejercicio del derecho al uso de ese espacio público e implican los grados en que se está incluido en la vida social de la ciudad. En otras palabras, el espacio público sólo existe en relación a la ciudad, la cual siempre actúa como un sistema, un todo que habilita el acceso a derechos primordiales. "Este derecho al espacio público se inscribe en el respeto a la existencia del derecho del otro al mismo espacio" (Carrión Mena, 2004, p. 61).

De esta manera, el espacio público se configura como el escenario en que cotidianamente se producen intercambios, diálogos e interacciones pero también donde se despliegan relaciones de poder por el control de ese espacio y entre los sujetos que transitan en él. Es decir, "el espacio es uno de los lugares donde se afirma y se ejerce el poder" (Bourdieu, 1993, p. 120).

Uno de los aspectos en que se manifiesta la pretensión de ejercer ese poder por parte del sistema judicial, en relación al uso que los migrantes hacen del espacio público en la ciudad de Buenos Aires, es el de la persecución de la venta callejera que realizan los extranjeros. Diversas son las instancias represivas que intervienen en el control de esta conducta catalogada como desviada: la policía, la Unidad Administrativa de Control de Faltas y la Justicia de la Ciudad de Buenos Aires. Este entramado institucional califica, clasifica y sanciona rutinaria y cotidianamente a sectores desfavorecidos de migrantes que ejercen una actividad económica en el espacio público. En ese encadenamiento de procederes, el extranjero -así como también nativos pobres- es colocado en una situación vulnerable. 
El asedio constante que viven los vendedores callejeros tiene como uno de sus objetivos regular la ocupación de los espacios para la actividad de comerciar, dado que la misma entra en contradicción con derechos (de propiedad) vinculados con su desarrollo de modo legal. Resulta ser que en el espacio público, concebido sólo como un lugar de tránsito, pueden ocurrir interrelaciones momentáneas pero no permanentes, mientras que -contrariamente- la actividad comercial de los vendedores, en este caso migrantes pobres, precisa de la presencia física y prolongada en el tiempo para su ejercicio. Por ende, este hecho supone un uso ilegítimo de ese espacio, ya que se convierte en un lugar donde esos sectores sociales "resuelven" necesidades que, desde la perspectiva de los sectores integrados, deberían encontrar "soluciones privadas". En términos de Taylor, Walton \& Young (2007, p. 148)

En una sociedad privatizada [...] cualquiera que pasa demasiado tiempo en un espacio público es blanco de sospechas. El espacio público está sumamente vigilado precisamente porque moverse en él equivale a ser sospechoso. Pasar mucho tiempo en el espacio público indica que no se está integrado en la trama cultural de la sociedad en la medida considerada conveniente, con lo que se da a la policía, y a otros, una pista acerca de la desviación potencial de la propia identidad.

Nuevamente, la idea de identidad y de cultura del extranjero resulta ser una variable explicativa, en este caso, de la desviación en el uso "apropiado" del espacio público. Cosacov E Perelman (2011) plantean que los espacios son portadores de moralidades, de ello resulta que no acatar las normas consideradas "correctas" y "decentes" supondrá la aplicación de una pena. El usuario legítimo del espacio público es aquel que puede hacer uso del mismo sin ser percibido, ya que su forma de actuar en ese espacio es la "normal", la esperada, la anhelada. De esta manera, existe una barrera simbólica que determina a priori lo que un habitante puede o no hacer.

[...] lo que sí creo que pasa es que en el caso de la ciudad es que los grupos migratorios, especialmente los países como Bolivia y $\mathrm{Pa}$ raguay, donde existe una cultura más del emprendedorismo y de la autogestión... se encuentran con este problema de que vender en 
la vía pública es una contravención [...] lo único que se me ocurre es esto de las contravenciones, que tiene que ver más con el impacto cultural que genera una migración acá (Entrevista a Escribiente, 2 años en el sistema judicial, 2010).

El estigma de seres excluidos que "escogen" dedicarse a este tipo de actividades económicas ensombrece la identidad de determinados grupos de migrantes. En este sentido, la venta callejera es asociada con el desorden y la suciedad, generando una suerte de "inseguridad sanitaria" (Cosacov \& Perelman, 2011, p. 311). Es así que no sólo se identifica a los migrantes con personas peligrosas por temor a que ocasionen daño físico o material, sino que se las considera sujetos poco higiénicos, que no respetan normas de sanidad y que mayormente están complacidos de dedicarse a este tipo de actividades laborales:

[Los bolivianos] tienen otro cuidado y otra manera de llevarse con lo público, que hay un choque cultural muy importante, sucios, que ensucian bienes públicos; que tiran deshechos en la vía pública; cortan calles; los domingos son difíciles -en Liniers- que se suelen divertir bastante y dejan todo un poquito desordenado. Básicamente son contravenciones o faltas (Entrevista a Secretario, Director Oficina de Atención a Víctimas, 12 años en el sistema judicial, 2010).

[...] en Liniers hay como un mini-barrio de bolivianos y ahí se acrecentó bastante. Eso lo veo, todos los días que paso por ahí, y ahí sí aumentó bastante, influyó. Impactó en el sentido de que aumentó la cantidad de delitos, o sea, en este sector que yo veo, por ejemplo en esta zona es terrible la cantidad de delitos que hay todo el tiempo, todo el tiempo, desde la venta ambulante en la calle desde robos, que son así menores de saqueos en la calle a las personas, o sea caminar por Liniers es un desastre y creo que hay otras zonas en capital donde también influyó [...] de hecho yo trabajaba en una fiscalía hace algunos años y venía mucha gente que era extranjera como imputados, ¿no?, entonces influyó, no eran sólo argentinos, había un porcentaje alto de extranjeros que estaban imputados por delito y contravenciones (Entrevista a Secretaria, 5 años en el sistema judicial, 2010).

$\mathrm{Al}$ respecto, Taylor et al. (2007, p. 145) sostienen que "una sociedad que no puede o que no quiere proporcionar a su población una cantidad 
suficiente de empleos o espacio donde vivir es una sociedad que necesita tomar como víctimas propiciatorias y rotular a una cantidad cada vez mayor y más variada de individuos".

Sí. Los senegaleses son los que están realizando venta ambulante. Por eso digo, la venta ambulante es una de las contravenciones en la que uno ve mayor cantidad de personas extranjeras. En la venta ambulante y en la oferta de sexo. En la oferta de sexo: dominicanas, paraguayas (Entrevista a Secretaria, 12 años en el sistema judicial, 2010).

Asimismo, sancionar este tipo de uso del espacio público manifiesta renovadamente la relación desigual de poder y dominación entre migrantes y el sistema judicial. Frente a este escenario, el espacio público resulta un lugar hostil para los migrantes, ya que sus prácticas (las "reales" y las "imaginadas" por los entrevistados) son valoradas negativamente y perseguidas con la aquiescencia legal. Ello ocurre también con determinadas manifestaciones culturales que son percibidas como contrarias al "buen empleo" del espacio público.

Tiene que ver más con cuestiones culturales. No es un delito, pero se vive denunciando a la comunidad boliviana en la zona de Liniers porque tienen otro tipo de costumbres, de alimentación, de fiestas populares y de lo que sea (Entrevista a Secretario, Director Oficina de Atención a Víctimas, 12 años en el sistema judicial, 2011).

En líneas generales, las representaciones sociales de los nativos se insertan en una concepción específica de concebir la ciudad y el espacio público, que comparte cierta simetría con la perspectiva que

[...] observaría a la ciudad como el lugar de residencia propio de la "gente decente", como la "vidriera del país" como el ámbito físico que devuelve y afirma valores de orden, equidad, bienestar, pulcritud, ausencia -al menos visible- de pobreza, marginalidad deterioro, y sus epifenómenos (delincuencia, subversión, desborde popular.) (Oszlak, 1991, p. 29).

En suma, la construcción de un imaginario en el que los migrantes sean considerados como un "problema" o un asunto que se preferiría no 
tener, resulta evidente en el análisis. La presencia de colectivos de migrantes regionales, fundamentalmente resulta ser, para los miembros del sistema judicial entrevistados, una situación a resolver dada su asociación con el desorden, el delito, las faltas a la moral argentina, la inseguridad, etc. En este marco, la diversidad se torna conflictiva y la relación intercultural entre nativos y migrantes, al ser asimétrica, resulta ser generadora de estigmatización y desigualdad. La figura 2 presenta la network (Representaciones sociales sobre la "peligrosidad migrante") resultante del procesamiento y análisis de las entrevistas, graficándose de modo resumido las diversas dimensiones analizadas hasta aquí.

Figura 2. Network de Representaciones sociales sobre la "peligrosidad del migrante"

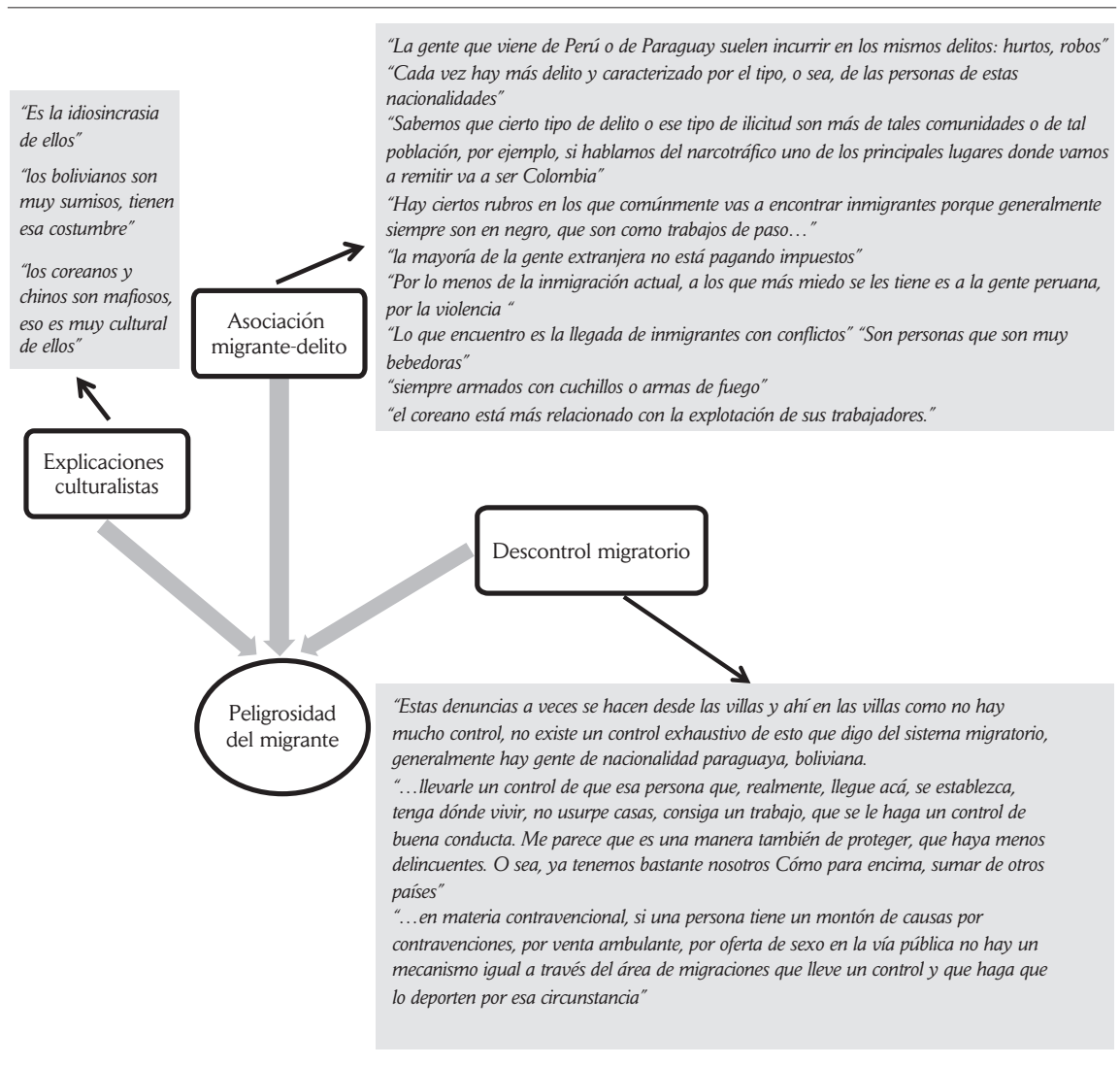

Fuente: elaboración propia a partir el análisis de las entrevista de Proyecto UBACYT, 2010-2014 


\section{Conclusiones}

Las páginas precedentes tuvieron como objetivo principal presentar los resultados de una investigación cuya unidad de análisis fue el sistema judicial, focalizado en una porción del poder judicial de la Ciudad Autónoma de Buenos Aires, que interviene en contravenciones, faltas y una serie limitada de delitos penales, tales como usurpaciones, uso indebido del espacio público, lesiones, etc. En este sentido, siendo parte de una de las instituciones estatales que debe aplicar las normas jurídicas que "ordenan" a la sociedad, no puede soslayarse su función normalizadora.

En el caso de los extranjeros, su sola presencia entre "nosotros" supone el establecimiento de relaciones interculturales que, si bien pueden caracterizarse por el diálogo, el encuentro armónico y el intercambio enriquecedor de la diversidad, también suponen un aspecto conflictivo. Es este último el que fue objeto de indagación.

En instituciones como la judicial, donde los procedimientos están signados por la repetición y la monotonía, los procesos de estigmatización y prejuicio pueden pasar desapercibidos con mayor facilidad. Consecuentemente, la naturalización de procederes y prácticas excluyentes adquieren un cariz dulcificado, tenue y, en ocasiones, imperceptible. La indagación y el análisis a partir de las representaciones sociales de los miembros del poder judicial tuvieron como fin hacer visible - no sin dificultades- lo no-dicho, lo oculto tras lo rutinario del trabajo judicial.

De este modo, se ha pretendido reconstruir la mirada de los miembros del sistema judicial acerca de los migrantes internacionales que, lejos de ser aséptica, se encuentra repleta de sentidos. De tal forma, el migrante es un sujeto que genera sospecha cuando menos, fundamentalmente los "asiáticos" (migración evidenciada como "exótica" y "hermética") y los regionales (fundamentalmente limítrofes - de Paraguay, Bolivia,y Perú), todos ellos asimilados como "migrantes pobres":

Lo que se ve con los sectores chinos, es la falta de integración con el tema del idioma. [...] No es gente que no entienda, sino que no quiere darse a entender (Entrevista a Secretario, 10 años en el sistema judicial, 2010). 
La migración limítrofe, como en el resto de la sociedad, y en determinados niveles, cierto prejuicio seguramente hay sobre determinados sectores y determinados migrantes - que son todos migrantes limítrofes-. Cierto prejuicio hay, creo yo, simplemente por una cuestión clara de diferente idiosincrasia. El poder judicial, está mayormente integrado por clase media profesional, de alguna manera, y la migración, viene de otro tipo de estamento y con otro tipo de costumbre muy diferentes. Lo que implica un choque de valores y, a veces, una dificultad en entender ese tipo de valores, ese tipo de costumbres (Entrevista a Secretario, 12 años en el sistema judicial, 2011).

Bauman (1996) ha catalogado al extranjero como un miembro de los innombrables, porque no es ni amigo ni enemigo, está entre nosotros pero no es parte de nosotros "desde siempre", "recae sobre él el pecado de la llegada tardía". En vinculación con la ley penal, el extranjero representa el desviado de la norma, aquel que por su posibilidad siempre latente de partir pareciera no internalizar ni importarle las pautas y leyes de la comunidad nacional. En las entrevistas, pudo evidenciarse esta cuestión cuando se ensayan explicaciones culturalistas acerca de por qué los extranjeros quebrantan las reglas nativas, ya sean delitos, contravenciones o simples faltas a "la moral y las buenas costumbres", dichas infracciones son vinculadas por los entrevistados con rasgos propios de las "culturas" de origen del migrante, acreditándose así la existencia de un "racismo cultural".

Una cuestión cultural que, lamentablemente, el funcionario judicial, ve a uno como un par, y ve al otro como un extraño. No, obviamente que, obviamente que sí. Y es un grado más dentro de ese, de esa vulnerabilidad, y dentro de esa ajenidad de la diferencia cultural que con un nacional solamente es una diferencia cultural y económica y con un extranjero, además, dependiendo del extranjero hay diferencias culturales más fuertes (Entrevista a Secretario, Director Oficina de Atención a Víctimas, 12 años en el sistema judicial, 2011).

Para la construcción de los extranjeros como sujetos peligrosos y la necesidad de su normalización, es activado un mecanismo que implica ubicar al "otro" como una amenaza, ya sea porque supone un daño a la 
integridad física de los nativos o a la propiedad privada o porque atenta contra la identidad del "nosotros".

En un contexto en que se ha sancionado a nivel local una ley migratoria superadora de la criminalizante y autoritaria normativa anterior, los desafíos de su aplicación abren el interrogante acerca de cómo las diversas instancias estatales desarticularán imaginarios acerca de los migrantes y las migraciones entendidas como un "problema". Analizar espacios donde se definen y establecen relaciones de micropoder, aunque no impliquen directamente la aplicación de la normativa nacional vinculada a las migraciones, supone repensar el modo en que los Estados administran y gestionan la diversidad en el día a día. Asimismo, a nivel de lo que acontece no solo en Argentina, sino a nivel mundial, en que la pluralidad de las sociedades es reconocida y el valor de la diversidad hasta es enaltecido, al tiempo que se reproducen expulsiones y reforzamiento de las fronteras nacionales en muchos países, la disyuntiva pareciera estar entre políticas migratorias y gestión interestatal de las migraciones a partir de un enfoque de derechos humanos o de una regulación de los flujos migratorios con una perspectiva en la que la "seguridad" de las sociedades de llegada sea el imperativo máximo, todo ello con las consecuencias que una u otra opción pudieran tener en las vidas de hombres y mujeres que migran con el afán de encontrar mejores condiciones de existencia.

En lo que respecta al presente artículo, tuvo la acotada pretensión de evidenciar de qué modo las representaciones prejuiciosas denotan determinadas regularidades en el universo analizado, tales como: la asociación representacional de cierto grupo migratorio con determinado delito (por ejemplo, colombianos con narcotráfico, chinos como mafiosos, paraguayos con delitos violentos, etc.), "características" de la personalidad de los extranjeros (violentos, ilegales, sucios, ladrones, etc.) atribuidas a toda la colectividad producidas por sus "idiosincrasias" o "culturas" que, según los entrevistados, explicarían además la comisión de determinados ilegalismos y, por último, el anclaje de dichas representaciones en el uso "inapropiado" del espacio público que realizarían los extranjeros.

En este sentido, podemos concluir que los prejuicios, entendidos como determinadas "opiniones dogmáticas y desfavorables respecto a ciertos grupos, y por extensión, respecto a miembros individuales de estos grupos" (Billig, 1986, p. 576), se sedimentan discursivamente en una 
imagen del extranjero como potencial peligro para la sociedad receptora, ubicando así al migrante, dentro de la configuración social, en una posición vulnerable, en tanto posible "chivo expiatorio" de las problemáticas (en este caso de inseguridad) que pudieran perturbar a la sociedad receptora.

\section{Referencias}

Argentina, Congreso de la Nación. Ley N. ${ }^{\circ} 25871$, de migraciones (17 de diciembre de 2003).

Argentina, Legistatura de la Ciudad Autónoma de Buenos Aires. Ley N. 1472, código contravecional (23 de septiembre de 2004).

Baczko, B. (1999). Los imaginarios sociales: memorias y esperanzas colectivas. Buenos Aires: Nueva Visión.

Balibar, E. (1991). ¿Existe un neoracismo? En E. Balibar \& I. Wallerstein, Raza, nación y clase (pp. 31-61). Madrid: IEPALA.

Balibar, E. (2005). Violencias, identidades y civilidad. Barcelona: Gedisa.

Bauman, Z. (1996). Modernidad y ambivalencia. En J. Berian (Coord.), Las consecuencias perversas de la modernidad (pp. 73-119). Barcelona: Anthropos.

Berger, T. \& Luckmann, P. (2006). La construcción social de la realidad. Buenos Aires: Amorrortu.

Billig, M. (1986). Racismos, prejuicios y discriminación. En S. Moscovici, Psicologia Social. Barcelona: Paidós.

Bourdieu, P. (1993). La miseria del mundo. Argentina: FCE.

Bourdieu, P. (2000). Elementos para una sociología del campo jurídico. En P. Bourdieu \& G. Teubner, La fuerza del derecho. Bogotá: Siglo del Hombre Editores.

Caimari, L. (2007). La ley de los profanos. Delito, justicia y cultura en Buenos Aires. Buenos Aires: FCE.

Carrión Mena, F. (2004). Espacio público: punto de partida para la alteridad. En F. Velásquez (Comp.), Ciudad e inclusión: por el derecho a la ciudad (pp. 55-79). Recuperado de http://works.bepress.com/cgi/viewcontent.cgi?article $=110$ 9\&context=fernando_carrion

Cea D'Ancona, M. A. (2005). La exteriorización de la xenofobia. REIS (112), 197-203.

Cohen, N. (2010). Representaciones de la diversidad: trabajo, escuela y juventud. Buenos Aires: Ediciones Cooperativas. 
Cohen, N. (2004). El inmigrante externo y el ámbito laboral. En N. Cohen (Comp.), Puertas adentro: la inmigración discriminada, ayer y hoy (pp. 78-86). Buenos Aires: IIGG, FCS \& UBA.

Cohen, N. (2009). No es sólo cuestión de migrantes: migraciones externas y exclusión social. En S. Goinheix (Ed.), Conflictos y expresiones de la desigualdad y la exclusión en América Latina (pp. 109-136). Buenos Aires: El Aleph.

Cohen, N. E Mera, C. (2005). Relaciones interculturales: experiencias y representación social de lo migrantes. Buenos Aires: Antropofagia.

Cosacov, N. E Perelman, M. (2011). Modos de apropiación de la ciudad, conflicto y gestión del espacio urbano. La construcción de fronteras en la ciudad de Buenos Aires. En M. Di Virgilio, H. Herzer, G. Merlinsky E M. C. Rodriguez (Comp.) La cuestión urbana interrogada. Transformaciones urbanas, ambientales y politicas públicas en Argentina (pp. 291-318). Buenos Aires: Café de las Ciudades.

Costanzo, G. (2009). El diario de sesiones y los debates sobre las Leyes de Residencia y de Defensa Social: la criminalización del anarquismo. En S. Martini \& M. Pereyra (Eds.). La irrupción del delito en la vida cotidiana. Relatos de la comunicación politica (pp 93-106). Buenos Aires: Biblios.

De Giorgi, A. (2005). Tolerancia Cero: estratégias y prácticas de la sociedad de control. Roma: Virus Editorial.

Devoto, F. (2003). Historia de la inmigración en la Argentina. Buenos Aires: Sudamericana.

Fiscalía de la Ciudad de Buenos Aires. (s.f.) Recuperado de http://www.fiscalias. gob.ar/mision-y-funciones/

González, A. E Plotnik, G. (2011). ¿De la homogeneidad a la diversidad? La construcción de la otredad del migrante externo en el ámbito educativo. Propuesta Educativa, 35(20), 105-112.

Hall, S. (1997). Sin garantías. Trayectorias y problemáticas en estudios culturales. Popayán, Lima \& Quito: Envión Editores, IEP, Instituto Pensar \& Universidad Andina Simón Bolívar.

Jodelet, D. (1991). Representaciones sociales, un área de expansión. En D. Paez, C. San Juan, J. Romo \& A. Vergara (Eds.). SIDA: imagen y prevención. Madrid: Fundamentos.

Oszlack, O. (1991). Merecer la Ciudad: Los pobres y el derecho al espacio urbano. Buenos Aires: Cedes \& Humanitas.

Plotnik, G, E González, A. (2012). El sesgo de deseabilidad social en el abordaje del fenómeno de la discriminación en las relaciones interculturales: algunas 
reflexiones sobre las guías de pautas como "teorías en acto". VII Jornadas de Sociología de la UNLP (pp. 1-19). La Plata: UNLP.

Poder Judicial de la Ciudad Autónoma de Buenos Aires. (s.f.). Recuperado de http://www.ijudicial.gob.ar/breve-historia-del-poder-judicial/

Sabido, O. (2009). El extraño. En E. León, Los rostros del otro (pp. 25-57). Barcelona: Anthropos.

Santamaría, E. (2002). La incógnita del extraño. Barcelona: Anthropos.

Strauss, A. \& Corbin, J. (2002). Bases de la investigación cualitativa. Técnicas y procedimientos para desarrollar la teoría fundamentada. Bogotá: CONTUS \& Editorial Universidad de Antioquia.

Taylor, I., Walton, P. \& Young, J. (2007). La nueva criminología. Contribución a una teoría social de la conducta desviada. Buenos Aires: Amorrortu.

Van Dijk, T. A. (1997). Historias y racismo. En D. Mumby (Comp.) Narrativa y control social. Perspectivas criticas (pp. 163-189). Buenos Aires: Amorrortu.

Velasco Arroyo, J. C. (2001). Liberalismo y derechos de las minorías: una relación conflictiva. En F. Colom (Ed.). El espejo, el mosaico y el crisol (pp. 117-146). Barcelona: Anthropos.

Wieviorka, M. (1992). El espacio del racismo. Barcelona: Paidós.

Wieviorka, M. (2002). La diferencia cultural como cuestión social. En E. Terrén (Ed.). Razas en conflicto (pp. 277-292). Barcelona: Anthropos. 